\title{
Preparation of indium-doped zinc oxide nanoparticles by pulsed laser ablation in liquid technique and their characterization
}

\author{
Khawla S. Khashan ${ }^{1}$ (D) Maryam Mahdi ${ }^{1}$
}

Received: 4 August 2017/ Accepted: 14 September 2017/Published online: 20 September 2017

(c) The Author(s) 2017. This article is an open access publication

\begin{abstract}
Indium-doped zinc oxide (IZO) nanoparticles (NPs) are produced by pulsed laser ablation in liquid technique. The influence of indium doping on the sizing, structure, morphology and optical properties of nanoparticles was investigated using X-ray diffraction (XRD), transmission electron microscope (TEM), energy dispersive spectrum, UV-Visible and photoluminescence spectroscopies. The XRD results demonstrated that indiumdoped $\mathrm{ZnO}$ maintained a hexagonal wurtzite structure with a (002) preferential orientation. With reference to the TEM images, the particle size increased with an increase in the doping ratio, and the morphology varied from particle to aggregated spheres and then to NPs. The optical absorption spectra increased with an increase in In-doped concentration, while the band gap had reduced. In addition, the photoluminescence spectrum had a broad green emission from IZO nanoparticles.
\end{abstract}

Keywords Laser ablation in liquid · Nanocomposite - IZO nanocolloidal $\cdot$ Indium-doped $\mathrm{ZnO}$ materials

\section{Introduction}

$\mathrm{ZnO}$ is a direct wide band gap $(3.37 \mathrm{eV})$ semiconductor material, with high excitation binding of energy about $60 \mathrm{meV}$. Further, it is one of the II-VI semiconductor materials and hexagonal wurtzite crystal structure. Therefore, it has many applications in different fields

Khawla S. Khashan

khawla_salah@yahoo.com

1 Department of Applied Science, University of Technology, Baghdad, Iraq
(Ramamoorthy et al. 2016; Shinde et al. 2008; Chava and Kang 2017; Sugumaran et al. 2016; Poloju and Reddy 2013; Zubkins et al. 2013) to improve the electrical and optical properties of $\mathrm{ZnO}$ nanoparticles doped with different metals such as $\mathrm{Al}, \mathrm{Mg}, \mathrm{Cd}, \mathrm{In}$, and $\mathrm{Sn}$ by changing the band gap (Khashan and Mahdi 2017; Kumar et al. 2015; Bargougui et al. 2014; Yan et al. 2016). Presently, various methods are being used for synthesis of indiumdoped zinc oxide nanostructures such as chemical vapor deposition (Sharma and Jeevanandam 2014), chemical method (Khashan 2013; Ritala et al. 1996), thermal evaporation (Poloju and Reddy 2013), sol-gel (Zubkins et al. 2013), atomic layer epitaxy (Naghavi et al. 2000), pulsed laser deposition (Umer et al. 2012), spray pyrolysis (Shinde et al. 2008) and wire explosion (Hamad et al. 2016). However, the various chemical reactions needed and low throughput rate are shortcomings of production. Additionally, the thermal plasma method needs a complex method system with a high energy density, particularly strong gradients between the medium that carries the deposition precursor and thus the environment. The wire explosion method is not conventionally used for common industrial functions that have common results and it is expensive. Additionally, it is impossible to use such a method explicitly for various metals. It is primarily useful for those metals of high electrical conductivity that are simply available, within the thin wire type. Among alternative methods, the PLAL method is a top-down technique utilized for synthesis of different nanoparticles, which offers several advantages over other methods. This is because it is simple, clean, does not need extreme temperature and pressure, and can generate a new phase of nanocrystals with new compounds of nanostructure. The size and shape of the nanoparticle synthesis by laser ablation in liquid depends on the ablation parameters such as laser fluence, 
pulse width, repetition rate, ablation time, wavelength and liquid depth. This involves creation of nanostructure material due to pulsed laser to target submerged in solution surroundings (Ritala et al. 1996; Naghavi et al. 2000; Umer et al. 2012; Hamad et al. 2016; Khashan and Mohsin 2015; Khashan and Abbas 2016). Therefore, in this paper, the researchers have prepared colloidal of indium zinc oxide using laser ablation in liquid. The impacts of In doping on structural and optical properties were considered.

\section{Experimental details}

$\mathrm{ZnO}$ NPs suspension doping with different indium concentrations can be prepared using pulsed laser ablation in liquid (PLAL) methods. A pulsed Q-switched Nd: YAG nanosecond laser was used to produce the nanoparticles with the following parameters: wavelength $\lambda=1064 \mathrm{~nm}$, frequency $f=10 \mathrm{~Hz}$ and pulse width $\tau=9 \mathrm{~ns}$. The nanoparticle preparation technique included two steps; the first one for zinc oxide nanoparticles preparation, was achieved via laser ablation of a zinc target that was placed in the bottom of the quartz vessel immersed in a constant de-ionized water volume $(3 \mathrm{ml})$. This process was done using laser energy $(80 \mathrm{~mJ})$ with $(10 \mathrm{~min})$ ablation time. The second step of the doping process was achieved by replacing the zinc target with Indium plate using the surrounding liquid that contained the $\mathrm{ZnO}$ nanoparticles previously, and using the same laser energy with different ablation times 2-5 min. The target and glass container were rotated during the process. To get further information on the crystal structure of the prepared sample X-ray diffraction (XRD) technique (Philips PW, Japan), operation with $\mathrm{Cu} \mathrm{Ka}$ radiation source at $2 \theta$ angel $=10^{\circ}-60^{\circ}$ was used. The morphology, particle size and chemical compositions of the prepared sample were examined using transmission electron microscope (TEM) type CM10 PW 6020, Philips-Germany (Al-Nahrien University), and energy dispersive spectrum (EDS) spectroscopy. The optical absorption was obtained using the SHIMADZU (1800) double beam spectrophotometer. The photoluminescence spectrum of IZO NP samples was measured using $\mathrm{CW}(282 \mathrm{~nm})$, with wavelengths in the range of 500-700 nm.

\section{Results and discussion}

Figure 1 confirms the XRD patterns of undoped $\mathrm{ZnO}$ NPs, doped with different indium concentrations, in which it can be noticed that the XRD patterns of IZO are similar with $\mathrm{XRD}$ of pure $\mathrm{ZnO}$, and that they agree with standard cards of wurtzite structure (JCPDS: 00-036-1451 and JCPDS: 00-005-0642), due to similar ionic radii of $\operatorname{In}^{3+}(0.26 \AA)$ and $\mathrm{Zn}^{2+}(0.74 \AA$ ) (Ritala et al. 1996). $\mathrm{ZnO}$ and IZO films show a peak of (002) plane at $2 \theta=33^{\circ}$, which indicates that they have a preferential growth orientation along the $c$ axis perpendicular to the substrate surface, and increase with increasing indium dopant concentration. This means enhancing the crystalline of sample with indium doping (Hafdallah et al. 2011). At the same time, other peaks at $2 \theta=16.29^{\circ}, 29.75^{\circ}, 31.80^{\circ}, 36.43^{\circ}, 39.20^{\circ}, 43.86^{\circ}$ and $45.53^{\circ}$ corresponding to (200), (222), (100), (101), (110), (420) and (431) plans, respectively, observed with lower intensities, are as per results shown in Table 1 and are in agreement with data in Ritala et al. (1996), Umer et al. (2012) and Hafdallah et al. (2011). These peaks increased with increasing In concentration doping. Further, shifting of these peaks was noticed to higher angles due to substitution of $\mathrm{In}^{3+}$ ions at the $\mathrm{Zn}^{2+}$ stits (Chen et al. 2005).
Fig. 1 X-ray diffraction patterns of pure and $\mathrm{ZnO}$ NPs doped with different In concentration

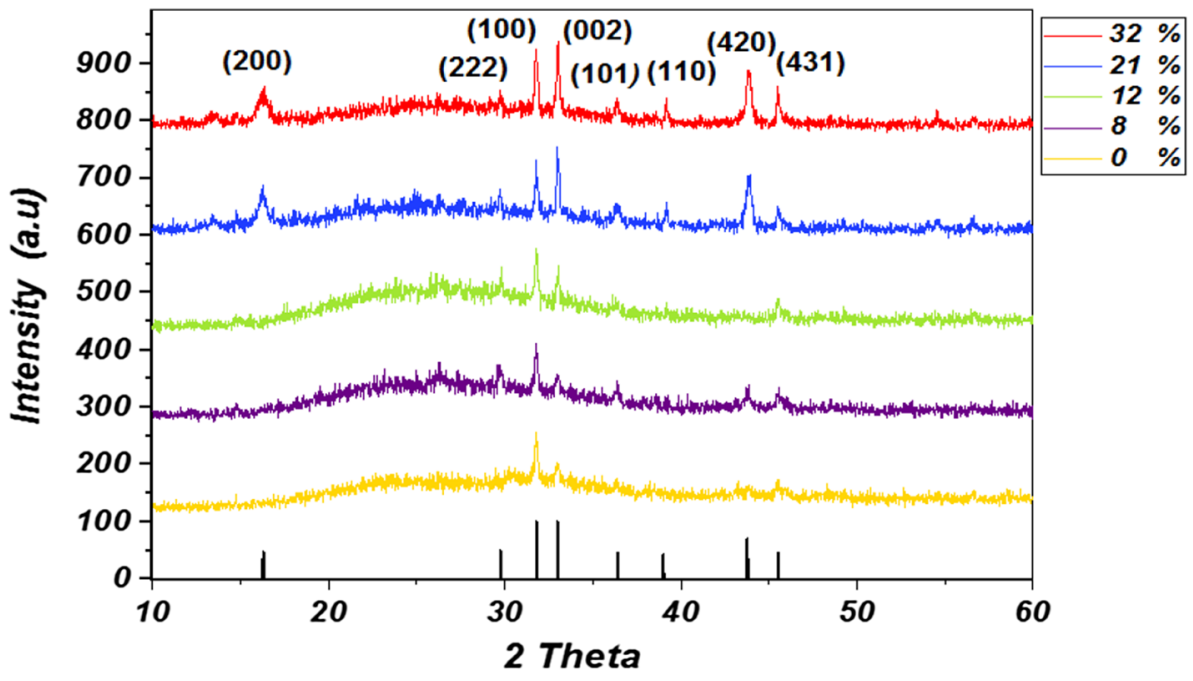


Table 1 Crystallite size from XRD

\begin{tabular}{|c|c|c|c|c|c|c|c|}
\hline \multirow[t]{3}{*}{$2 \theta$} & \multirow[t]{3}{*}{ Plane } & \multirow[t]{3}{*}{ Type } & \multicolumn{5}{|c|}{ Crystallite size $D(\mathrm{~nm})$} \\
\hline & & & \multirow{2}{*}{$\begin{array}{l}\text { Pure } \mathrm{ZnO} \\
0 \%\end{array}$} & \multicolumn{4}{|l|}{$\mathrm{IZO}$} \\
\hline & & & & $8 \%$ & $12 \%$ & $21 \%$ & $32 \%$ \\
\hline 16.29 & $(200)$ & $\mathrm{In}_{2} \mathrm{O}_{3}$ & 34.96 & 40.58 & 41.96 & 17.91 & 69.91 \\
\hline 29.75 & $(222)$ & $\mathrm{In}_{2} \mathrm{O}_{3}$ & 28.65 & 37.64 & 39.97 & 74.08 & 64.42 \\
\hline 31.80 & $(100)$ & $\mathrm{ZnO}$ & 27.56 & 33.08 & 35.98 & 70.03 & 71.96 \\
\hline 33 & $(002)$ & $\mathrm{ZnO}, \mathrm{In}$ & 39.35 & 37.64 & 40.64 & 48.61 & 64.9 \\
\hline 36.43 & $(101)$ & $\mathrm{ZnO}$ & 25.669 & 36.37 & 30.01 & 31.57 & 51.55 \\
\hline 39.20 & $(110)$ & $\mathrm{In}_{2} \mathrm{O}_{3}$ & 20.97 & 44.03 & 52.82 & 58.7 & 61.58 \\
\hline 43.86 & $(420)$ & $\mathrm{In}_{2} \mathrm{O}_{3}$ & 44.61 & 44.1601 & 46.79 & 63.72 & 76.05 \\
\hline 45.53 & $(431)$ & $\mathrm{In}_{2} \mathrm{O}_{3}$ & 24.84 & 36.18 & 37.43 & 64.17 & 79.3 \\
\hline
\end{tabular}

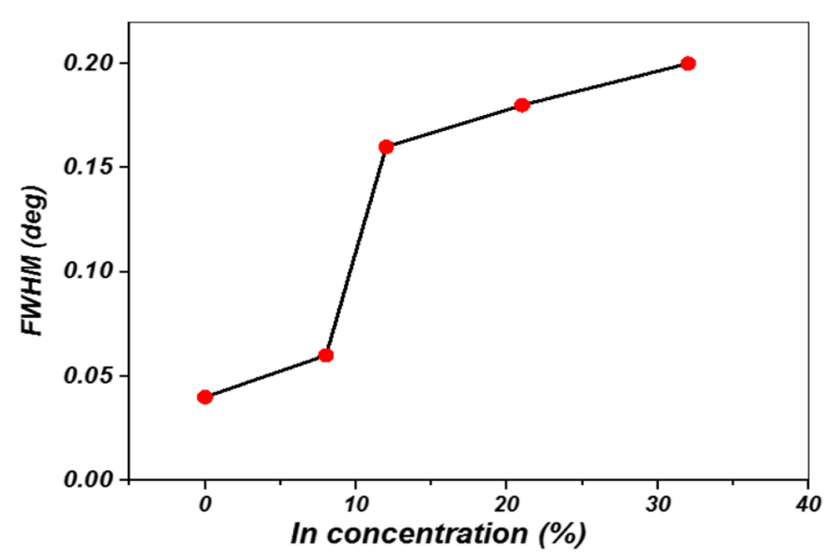

Fig. 2 The FWHM of (002) peaks for ZnO NPs doping with different In contact

Fig. 3 Variation of grain size of (002) peaks with doping level (\%wt)
Figure 2 shows the FWHM of (002) peaks, which increased as In concentration increased indicating the degeneration of crystalline quality of the ZnO NPs. This agreed with reference (Chen et al. 2009). The crystalline size of prepared samples was calculated for different miller indices, using Scherrer's formula: $\delta=\frac{0.9 \lambda}{B \cos \theta_{b}}$, as shown in Fig. 3. The crystalline size of (002) peak increased with an increase in indium content, which denotes that the Indium atoms were present at the $\mathrm{ZnO}$ lattice sites.

Figure 4 shows the TEM images of the undoped suspensions of $\mathrm{ZnO} \mathrm{NPs}$, doping with different In concentrations and particle distributes. It was observed that the pure zinc oxide $(0 \%)$ have nanostructures with sizing range from 1 to $11 \mathrm{~nm}$ and average size $2.9 \mathrm{~nm}$. For ZnO NPs doped with (12\%) In concentration, there were small spherical-like structures with particle size range 1-12 nm

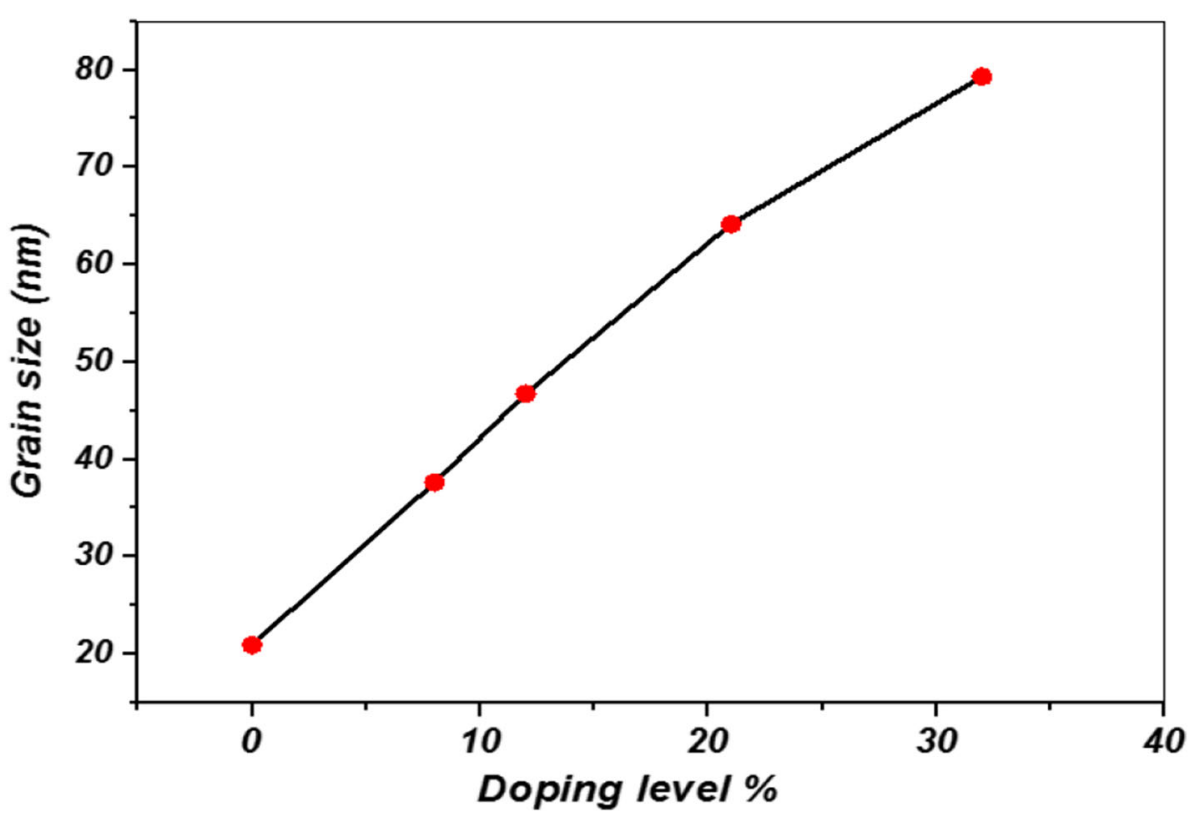





Fig. 4 TEM image of pure ZnONPs and doped with different In concentration

Table 2 Crystallite index of pure and doped $\mathrm{ZnO}$

\begin{tabular}{lcll}
\hline $\begin{array}{l}\text { Doping concentration } \\
\text { (indium at \%) }\end{array}$ & $\begin{array}{l}\text { Particle size } \\
(D) \text { nm TEM }\end{array}$ & $\begin{array}{l}\text { Crystallite size } \\
(D) \text { nm XRD }\end{array}$ & $I_{\text {cry }}$ \\
\hline 0 & 56 & 20.97 & 2.67 \\
12 & 68 & 30.1 & 2.26 \\
32 & 144 & 64.42 & 2.23 \\
\hline
\end{tabular}

and average size $3.4 \mathrm{~nm}$. Whereas, at $32 \%$ In concentration more particles of spherical-like structures with nanoparticle size ranging from 1 to $12 \mathrm{~nm}$ and average size $3.6 \mathrm{~nm}$ were detected. In addition, as exhibited from the images, with increasing In content, the morphology of products changed from particle to aggregated spheres and then NPs, and the particle sizes increased with an increase in the doping ratio.
These results were confirmed by XRD data and good agreement with reference Sugumaran et al. (2016). The crystallizing index $\left(I_{\text {cry }}\right)$ is calculated using formula: $I_{\text {cry }}=$ $\frac{D_{\text {cry }}(\text { SEM,TEM })}{D_{\text {cry }}(\text { XRD })} \quad\left(I_{\text {cry }} \geq 1.00\right) \quad$ (Zubkins et al. 2013). This determines that the material is a mono-crystalline if, $I_{\text {cry }} \approx 1$, and is poly-crystalline if, $I_{\text {cry }}>2$ as shown in Table 2 .

Figure 5 represents electron dispersive spectroscopy (EDS) analysis for zinc oxide doping with different indium concentration. It gives the weight percent of each ion, in particular $\mathrm{Zn}, \mathrm{O}$ and $\mathrm{In}$, ratio of In ions on $\mathrm{Zn}$, and $\mathrm{O}$ atoms in the lattice as shown in Table 3. Figure 6 shows the absorbance spectra for undoped $\mathrm{ZnO}$ nanoparticles, doped with different indium concentrations, where the peak 
Fig. 5 EDS for ZnO NPs doping with different In doping concentration
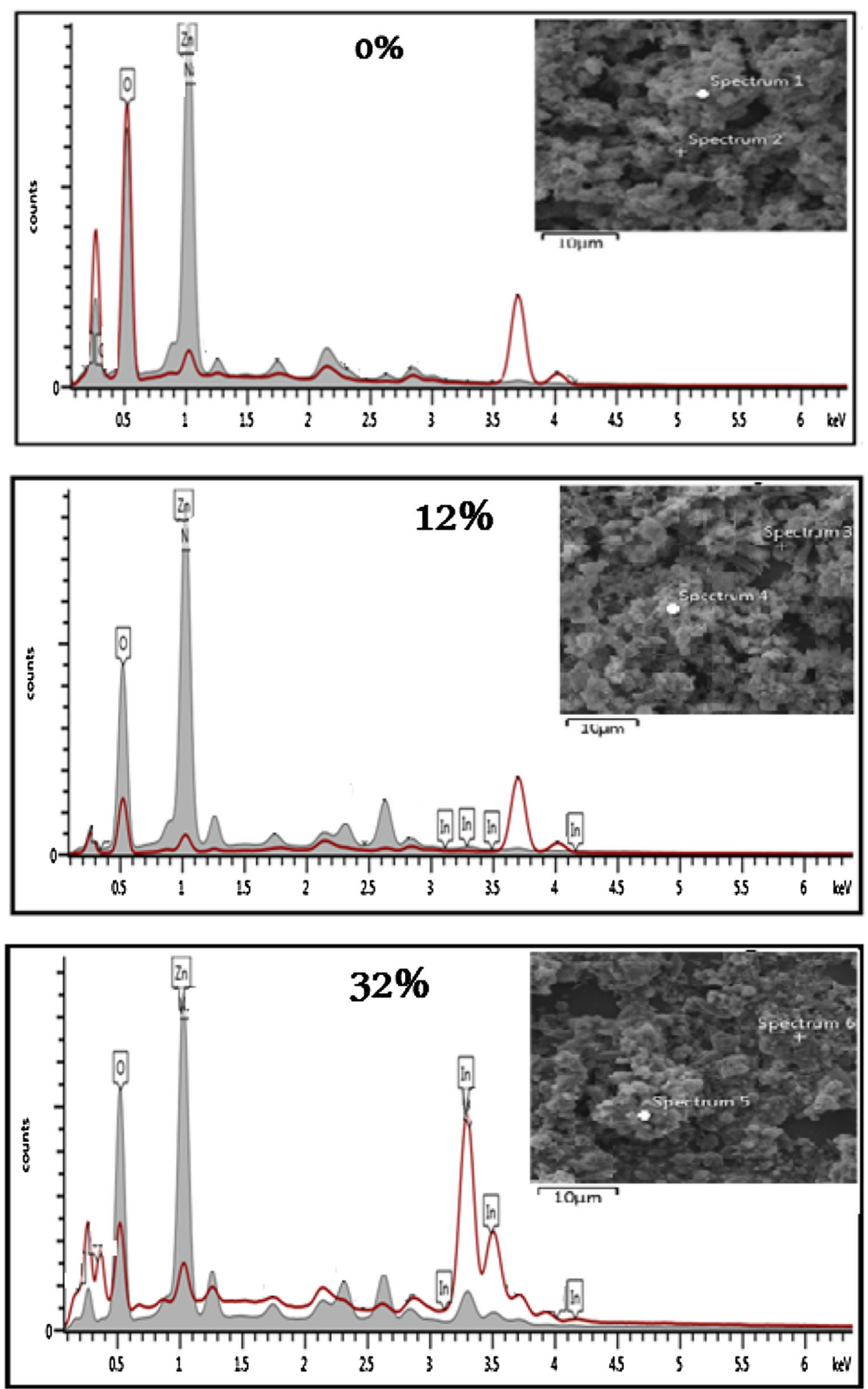

broads around $300 \mathrm{~nm}$, for pure ZnO NPs. After doping with indium, the absorption broad shifted a bit towards lower wavelengths in all doped samples, which means a red-shift in the absorption spectra (Tang et al. 2015). Moreover, it can be noticed that the increased absorption intensity is due to higher scattering of light on the rough surfaces of the doped nanostructures, that increased as In concentration increased.

Further, the synthesized NPs exhibited low absorption in the VIS range and high absorption in the UV range. This 
Table 3 EDS for ZnONP doping with different In contact

\begin{tabular}{lll}
\hline Doping concentration at $\%$ & Element & Weight \% \\
\hline 0 & O & 27.86 \\
& Zn & 56.52 \\
12 & In & 0 \\
& O & 23.21 \\
& Zn & 41.86 \\
32 & In & 2.06 \\
& O & 24.91 \\
& Zn & 27.84 \\
& In & 16.33 \\
\hline
\end{tabular}

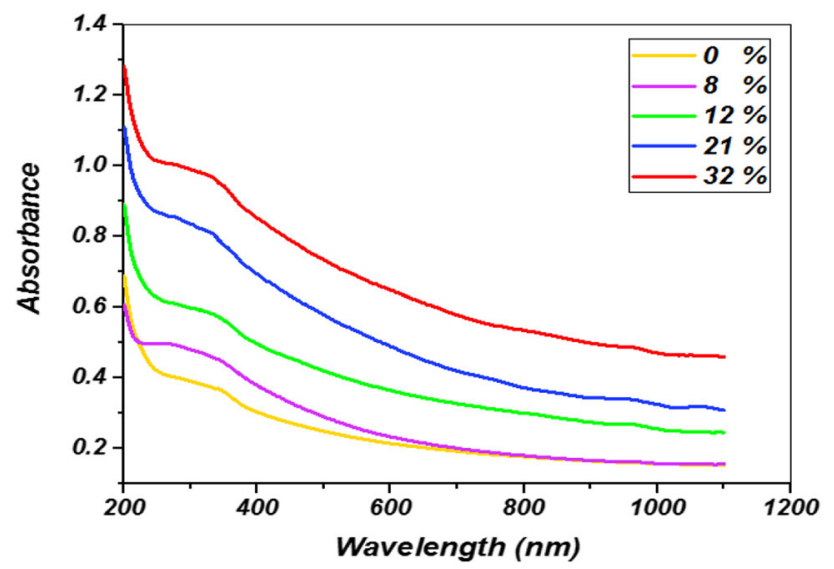

Fig. 6 UV-Vis absorbance spectra of ZnO NPs suspensions doped with different In concentration

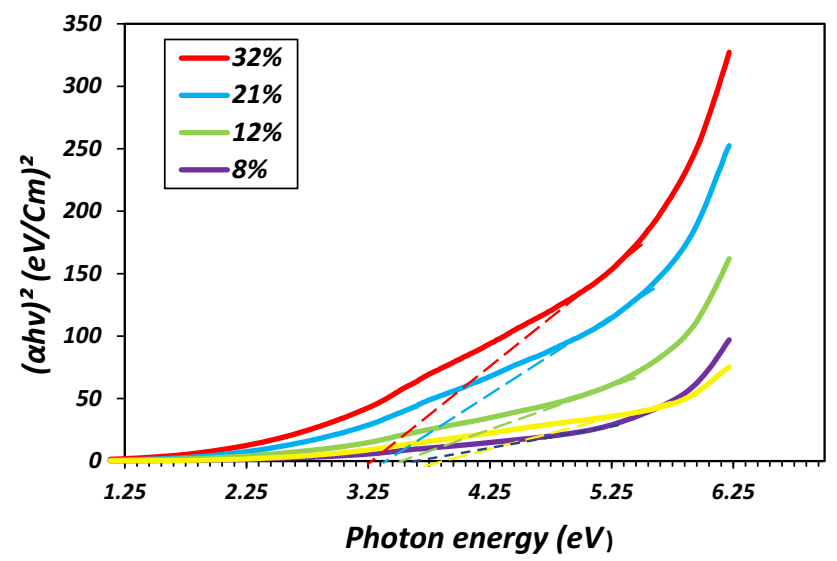

Fig. 7 Plot of $(\alpha h v) 2$ vs. $h v$ for $\mathrm{ZnO}$ NP suspensions doped with different In concentration

high absorption in the UV region can be due to the fundamental absorption and involves electron transition from the valence to the conduction band that shows the band gap of the semiconductor (Chava and Kang 2017). Figure 7 reveals the direct band gap values that were obtained by

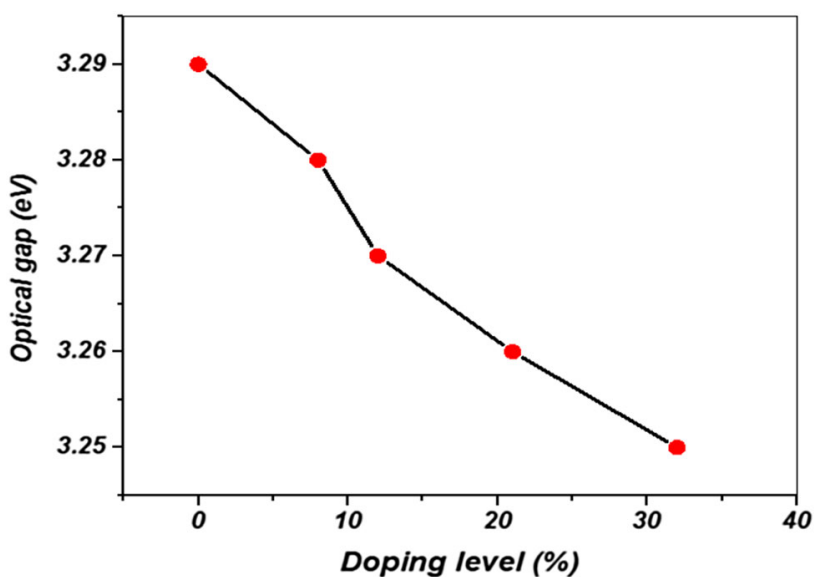

Fig. 8 Variation of optical band gap with doping level

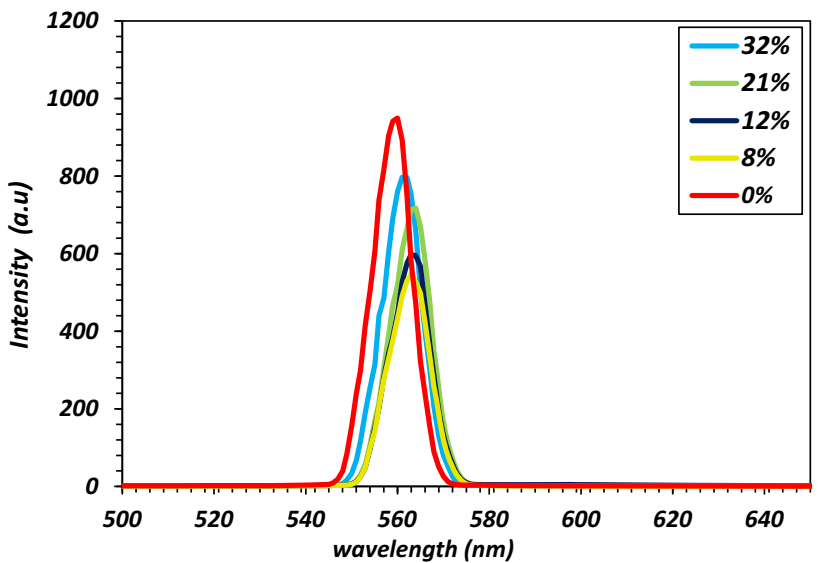

Fig. 9 Photoluminescence spectra of $\mathrm{ZnO}$ doping with different In concentration

extrapolating the linear part in a plot $(\alpha h v)^{2}$ against $h v$, the direct band gap semiconductor, which was given from the relation between the absorption coefficients, $(\alpha)$ and the incident photon energy $(h v)$ given by $(\alpha h v)^{2}=A\left(h v-E_{\mathrm{g}}\right)$, noting that the energy gap of $\mathrm{ZnO}$ NP suspensions before doping is $3.29 \mathrm{eV}$ and decreased to $3.25 \mathrm{eV}$ after using different indium concentrations (Fig. 8). These results were in good agreement with Chava and Kang (2017) and Tang et al. (2015). The band gap $E_{\mathrm{g}}$ shifts observed with doping, are due to concentration of majority carriers (Chava and Kang 2017) and changes in nanocrystal electronic structure. With regards to the semiconductor metal transition theory, the $E_{\mathrm{g}}$ reduces when the impurity is higher than the Mott critical density (Wander et al. 2001). Hence, doping leads to an obvious narrowing of the band gap. As the doped elements enter the $\mathrm{ZnO}$ crystal lattices, the localized band edge states form at the doped sites, with a reduction of $E_{\mathrm{g}}$ (Morales et al. 2006; Mehra et al. 2016). 
Table 4 The IZO photoluminescence band gaps

\begin{tabular}{llll}
\hline $\begin{array}{l}\text { Laser energy } \\
(\mathrm{mJ})\end{array}$ & $\begin{array}{l}\text { Doping } \\
\text { concentration at } \%\end{array}$ & $\begin{array}{l}\text { Optical band } \\
\text { gap }(\mathrm{eV})\end{array}$ & $\begin{array}{l}\text { Photoluminescence } \\
\text { band gap }(\mathrm{eV})\end{array}$ \\
\hline 80 & 0 & 3.29 & 2.135 \\
80 & 8 & 3.28 & 2.121 \\
80 & 12 & 3.27 & 2.125 \\
80 & 21 & 3.28 & 2.125 \\
80 & 32 & 3.25 & 2.132 \\
\hline
\end{tabular}

PL spectra of undoped and doped $\mathrm{ZnO}$ NPs were recorded at room temperature (excitation wavelength$282 \mathrm{~nm}$ ) as shown in Fig. 9. The undoped sample showed a very broad high intensity peak centered around $560 \mathrm{~nm}$, corresponding to the blue-green emission and, four additional emissions of 562, 562.05, 563.97 and $562.94 \mathrm{~nm}$ were observed for In-doped samples. The emission band of IZO NPs is related to the recombination of photo-generated holes with singly ionized charge states in intrinsic defect such as oxygen vacancies, impurities or $\mathrm{Zn}$ interstitial (Chen et al. 2009). The remarked green emission may be attributed to several intrinsic defects such as the oxygen vacancies, zinc vacancy $\left(\mathrm{V}_{\mathrm{Zn}}\right)$, oxygen antisite defects $\left(\mathrm{O}_{\mathrm{Zn}}\right)$, and surface electron recombination in addition to donor-acceptor pairs. When increasing indium doping concentration, it shifts to shorter wavelengths due to the size increase. This agrees well with the TEM results (Sharma and Jeevanandam 2014) as well as the photoluminescence peak intensity of zinc oxide nanoparticle decreases after indium doping (Ritala et al. 1996), which may be attributed to the increase in nonradiative recombination. Actually, this is the main reason for the narrowing of the optical band gap after indium doping, which may be attributed to conduction-band renormalization or a merging of the impurity band with the valence or conduction band (Mehra et al. 2016). The energy gap of IZO NPS is shown in Table 4.

\section{Conclusions}

According to the analysis above, it can be concluded that the IZO nanoparticles were synthesized by the PLAL process with different In concentrations. Nanoparticles perform a particle-like structure and the surface morphology is controlled by the In content. The crystal quality- and $c$-axis-preferred orientation of nanoparticles was improved via In content, particularly at $32 \%$ In. The values of $E_{\mathrm{g}}$ were decreased from 3.27 to $3.25 \mathrm{eV}$ with an increase in In content. Finally, the photoluminescence result exhibited a broad green emission of IZO NPs.
Open Access This article is distributed under the terms of the Creative Commons Attribution 4.0 International License (http:// creativecommons.org/licenses/by/4.0/), which permits unrestricted use, distribution, and reproduction in any medium, provided you give appropriate credit to the original author(s) and the source, provide a link to the Creative Commons license, and indicate if changes were made.

\section{References}

Bargougui R, Taher YB, Oueslati A, Hlel F, Ammar S (2014) Coprecipitation synthesis and $\mathrm{AC}$ conductivity of $\mathrm{Sn}_{0.94} \mathrm{Zn}_{0.04} \mathrm{O}_{2}$ nanoparticles, using impedance spectroscopy. J Mater Sci Mater Electron 25(12):5241-5247

Chava RK, Kang M (2017) Improving the photovoltaic conversion efficiency of $\mathrm{ZnO}$ based dye sensitized solar cells by indium doping. J Alloys Compd 692:67-76

Chen YW, Liu YC, Lu SX, Xu CS, Shao CL, Wang C, Zhang JY, Lu M, Shen DZ, Fan XW (2005) Optical properties of ZnO and $\mathrm{ZnO}$ : In nanorods assembled by sol-gel method. J Chem Phys 123(13): 134701

Chen KJ, Hung FY, Chang SJ (2009) Structural characteristic, Raman analysis and optical properties of indium-doped $\mathrm{ZnO}$ nanoparticles prepared by sol-gel method. J Nanosci Nanotechnol 9(5):3325-3329

Hafdallah A, Yanineb F, Aida MS, Attaf N (2011) In doped ZnO thin films. J Alloys Compd 509(26):7267-7270

Hamad AH, Khashan KS, Hadi AA (2016) Laser ablation in different environments and generation of nanoparticles. In: Yang D (ed) Applications of laser ablation-thin film deposition, nanomaterial synthesis and surface modification. InTech

Khashan KS (2013) Synthesis, structural and optical properties of CdS nanoparticles prepared by chemical method. Eng Technol J 31:39-48

Khashan KS, Abbas SF (2016) Characterization of InN nanoparticles prepared by laser as photodetector. Int J Mod Phys B 30(14): 1650080

Khashan KS, Mahdi F (2017) Synthesis of ZnO: Mg nanocomposite by pulsed laser ablation in liquid. Surf Rev Lett 24:1750101. doi:10.1142/S0218625X17501013

Khashan KS, Mohsin MH (2015) Characterization of carbon nitride nanoparticles prepared by laser ablation in liquid for optoelectronic application. Surf Rev Lett 22(04):1550055

Kumar AGS, Obulapathi L, Sarmash TS, Rani DJ, Maddaiah M, Rao TS, Asokan K (2015) Structural, electrical and optical properties of $\mathrm{Cd}$ doped $\mathrm{ZnO}$ thin films by reactive de magnetron sputtering. JOM 67(4):834-839

Mehra S, Bergerud A, Milliron DJ, Chan EM, Salleo A (2016) Core/ shell approach to dopant incorporation and shape control in colloidal zinc oxide nanorods. Chem Mater 28(10):3454-3461

Morales AE, Zaldivar MH, Pal U (2006) Indium doping in nanostructured $\mathrm{ZnO}$ through low-temperature hydrothermal process. Opt Mater 29(1):100-104

Naghavi N, Rougier A, Marcel C, Guery C, Leriche JB, Tarascon JM (2000) Characterization of indium zinc oxide thin films prepared by pulsed laser deposition using a $\mathrm{Zn}_{3} \mathrm{In}_{2} \mathrm{O}_{6}$ target. Thin Solid Films 360(1):233-240

Poloju M, Reddy MVR (2013) Proceedings of the "international conference on advanced nanomaterials \& emerging engineering technologies" (ICANMEET-20J3) organized by Sathyabama University, Chennai, India in association with DRDO, New Delhi, India, 24th-26th, July

Ramamoorthy K, Kumer K, Chandramohan R, Sankaranarayanan K (2016) Review on material properties of IZO thin films useful as

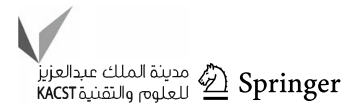


epi- $n$-TCOs in opto-electronic (SIS solar cells, polymeric LEDs) devices. Mater Sci Eng B 126:1-15

Ritala M, Asikainen T, Leskelä M, Skarp J (1996) Ale growth of transparent conductors. MRS Online Proc Libr Arch 426: 513-518

Sharma M, Jeevanandam P (2014) Synthesis, characterization and studies on optical properties of indium doped $\mathrm{ZnO}$ nanoparticles. Indian J Chem 53A:561-565

Shinde SS, Shinde PS, Bhosale CH, Rajpure KY (2008) Optoelectronic properties of sprayed transparent and conducting indium doped zinc oxide thin films. J Phys D Appl Phys 41(10):105109

Sugumaran S, Ahmad MNB, Jamlos MF, Bellan CS, Chandran S, Sivaraj M (2016) New possibility on InZnO nano thin film for green emissive optoelectronic devices. Opt Mater 54:67-73

Tang K, Gu S, Liu J, Ye J, Zhu S, Zheng Y (2015) Effects of indium doping on the crystallographic, morphological, electrical, and optical properties of highly crystalline $\mathrm{ZnO}$ films. J Alloys Compd 653:643-648

Umer A, Naveed S, Ramzan N, Rafique MS (2012) Selection of a suitable method for the synthesis of copper nanoparticles. Nano 7(05):1230005
Wander A, Schedin F, Steadman P, Norris A, McGrath R, Turner TS, Thornton G, Harrison NM (2001) Stability of polar oxide surfaces. Phys Rev Lett 86(17):3811

Yan XY, Yao CB, Li J, Hu JY, Li QH, Yang SB (2016) Structural, photoluminescence and picosecond nonlinear optical effect of In-doped $\mathrm{ZnO}$ nanowires. Opt Mater 55:73-77

Zubkins M, Kalendarev R, Vilnis K, Azens A, Purans J (2013) Structural, electrical and optical characteristics of Al-doped zinc oxide thin films deposited by reactive magnetron sputtering. In: IOP conference series: materials science and engineering, vol 49, p 012057

\section{Publisher's Note}

Springer Nature remains neutral with regard to jurisdictional claims in published maps and institutional affiliations. 